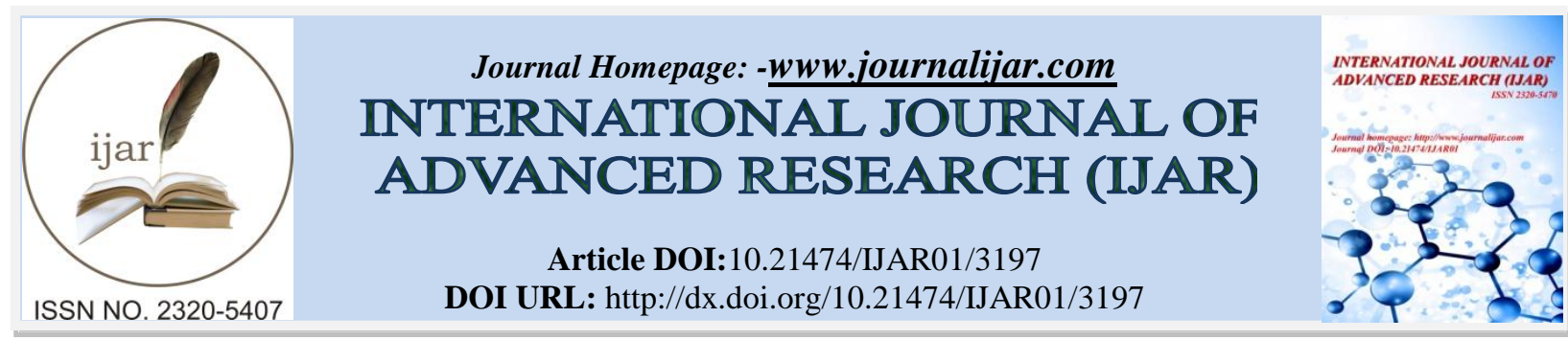

RESEARCH ARTICLE

\title{
AWARENESS ABOUT EPILEPSY IN CHILDREN AMONG SCHOOLTEACHERS IN RIYADH, KSA
}

\author{
Hadeel B. Alkahil, Yara M. Falatah, Merna M. Abdulbaki, Youssef F. Horaib, RanaS. Alaskar, Lamyaa M. \\ Alomar, Shuaa M. Alduraibi and Amnah A. Alhazmi. \\ Department of Pediatrics, Medical College, Al Maarefa Colleges, Riyadh, KSA.
}

\section{Manuscript Info}

Manuscript History

Received: 07 December 2016

Final Accepted: 22 January 2017

Published: February 2017

Key words:-

Awareness, Epilepsy, Seizure, Children, School Teachers, First Aid, Impact on Health.

\section{Abstract}

Introduction: Epilepsy is a brain disorder characterized by a pathological abnormality in electrical activity of the brain resulting in an unprovoked abnormal movement or behavior leading to a neurobiological, cognitive, psychological, and social consequence. The level of public awareness, and the attitudes and knowledge of epilepsy in the Saudi population is limited, and requires significant improvement.

Objective: This study aimed to assess the awareness about the definition of epilepsy in pediatric ages, types of epilepsy, managing an epileptic fit in children and awareness about the impact of epilepsy on children's educational and social performance among schoolteachers.

Methodology: 320 teachers were selected from different schools in Riyadh city KSA by a cross-sectional study. The data collected by 14 Statement questionnaires including our objectives.th data reviewed, and statistically analyzed using percentages and frequencies.

Result: the results show that $99.4 \%$ of teachers have heard about epilepsy, Most of the teachers want to learn more about epilepsy, and about $73 \%$ of teachers know that one type of seizure is generalized seizure, $35.9 \%$ know partial seizure. More than the half of the teachers has been a witness of an epileptic fit in their classes and around $43 \%$ of teachers' first reaction to an epileptic fit was trying to help. The first aid in epileptic fit, is to put a soft towel in the mouth to protect the tongue and keep airway open was $70 \%$, and $46.3 \%$ think to secure the media around the patient. The media $38 \%$ encountered the most frequently as source of knowledge and an abnormal electrical activity in the brain $70.3 \%$ as cause of epilepsy.

Conclusion:This study has revealed a critical issue that a majority of schoolteachers do not have adequate knowledge about epilepsy. We recommend the mandatory implementation of epilepsy and basic lifesupport training and refreshing courses for all schoolteachers across KSA. In addition to enrolling in training courses, teachers must be aware of the availability of first aid kits at schools and the contact numbers of the Saudi Red Crescent Services.

Copy Right, IJAR, 2017,. All rights reserved. 


\section{Introduction:-}

Epilepsy is a common neurological disorder in Saudi Arabia, with a prevalence of 6.54 per 1000. The level of public awareness, and the attitudes and knowledge of epilepsy in the Saudi population is limited, and requires significant improvement ${ }^{1}$.Epilepsy is a brain disorder characterized by a pathological abnormality in electrical activity of the brain resulting in an unprovoked abnormal movement or behavior leading to a neurobiological,cognitive, psychological, and social consequence ${ }^{2}$. Epilepticseizures can be dividedinto two major classes,Partial-onset seizureis a seizure that begins on a focal area of the cerebral cortex. This class is further categorized as simple focal seizure the main characteristicthing aboutthis seizure is that the level if consciousness is persevered. This type of seizures has subtypes, whichare sensory,motor,autonomic,and psychic. Complex focal seizure; unlike simple complex seizure in this type of seizure there is an impairment of consciousness, those patientsusually have an aura before theirseizure and this aura is usually the simple focal seizure, ittypically begins with a behavioral arrest fallowed by staring,automatism and postictal confusion. Secondary generalized seizureoften begins with an aura then proceeds to complex focal seizure and then to generalized tonic colonicseizure.

\section{Generalized onset seizure;these are classified into six major categories:-}

Absenceseizure; briefepisodesof blank staring with impaired consciousness, it's without aura or postictal confusion. Myoclonicseizure; briefarrhythmic jerking motor movementColonicseizure; consist of rhythmic jerking motor movement with or without impairment of consciousness. Tonicseizure; sudden onset of tonicextension or flexion of the head, trunk andextremities for severalseconds. Primary generalized tonic - colonicseizure (grand mal seizure); they consist of several motor behaviors, including generalized tonic extension of the extremities lasting few seconds fallowed by colonic rhythmic movement and prolonged postictal confusion Atonicseizure(drop attacks); brief loss of postural tone often results in fall and injures.It is very important to know how to deal and handle anepilepticfit. When you see a person with an epileptic fit the first thing to do is, protect them from injury by removing harmfulobject,then cushion their head and time the length of the jerking movement, aid the breathing by gently placing the body in the recovery position, once the jerking have stopped, then stay with them until they fully recover, it is very important not to put anything in their mouth or try to restraintheirmovement, don't give them anything to eat or drink until they are fully recovered ${ }^{(2)}$. Epilepsy is a complex disorder that has an impact on many aspect of child's development, and school personals may have basic understanding about seizure and its related safety concerns but have less knowledge about the impact of seizure on child's emotional, behavioral and social adjustment.As a result, these children are at increased risk of learningdifficulties and unsuccessful school experience; they might face difficulty in social engagement with friends and inadequate social skills and poor selfsteam. And that's why it's important for educators and family members and health care providers to partnership in the care of those children and provides a plan for academicsuccess and safety ${ }^{3}$. A study was done on Kuwait among 824 teacher in 2016, about "Knowledge about Epilepsy and Attitudes toward Students with Epilepsy among Middle and High School Teachers in Kuwait", by cross-sectional study and randomly selected schools, and its show that there is a relatively poor knowledge about epilepsy among school teacher but they have positive attitudes toward students with epilepsy ${ }^{4}$.In 2015 a study about "Knowledge and practice of schoolteachers towards students with epilepsy in Khamis Mushate, Southern Saudi Arabia”, among 315 male teachers. It shows that about three-quarters of schoolteachers had attended epileptic fits. About half of them believed that electrical discharges caused epilepsy. Most of them were not with teaching epilepsy separately, nor preventing them from activity. More than half of schoolteachers were not able to do first aid of seizure attacks ${ }^{5}$.In 2015 a study about "Knowledge and attitudes toward epilepsy among school teachers in West of Iran", conduct on 305 teachers from 25 schools. The study shows that the majority of schoolteachers heard about epilepsy. There were positive Attitude and knowledge about epilepsy, but there were deficits in first-aid of epileptic fit ${ }^{6}$.In 2014 a study about "Knowledge, attitude and practices of school teachers towards epileptic school children in Karachi, Pakistan". Among 120 teachers, it was showed that majority of the teachers heard about epilepsy, $14.5 \%$ of them think epilepsy is contagious while $72.7 \%$ see that epileptics children can succeed as other normal children. A $62.7 \%$ were willing to help if they attend epilepsy fit ${ }^{7}$. A study was conducted in 2013 by authors in King Abdulaziz University, Jeddah, about "Primary school teacher's knowledge and attitudes toward children with epilepsy", show that $17 \%$ of the teachers well informed about epilepsy. And according to the teachers' attitude, they found that it depends on teachers' knowledge, about $58 \%$ of teachers whom happened to have epileptic students in their class, didn't know what to do whenthey came across an acute seizure in the classroom as their first seizure attack they face ${ }^{8}$.A study was conducted on a sample of a 259 teachers and counselors in 2012 about "Knowledge and attitudes toward epilepsy among school teachers and counselors in Jordan". The results showed average knowledge of epilepsy, however they have poor knowledge about how to deal epileptic person ${ }^{9}$. A study in Pilsen, Czech Republic, that was published in 2012 about "Familiarity with and attitudes towards epilepsy among teachers at Czech elementary schools-The effect of 
personal experience and sub specialization". They found significant differences between the teachers with and without personal experience in the aspect of their attitudes. Teachers without personal experience were convinced that epileptic student were more likely to have psychological problems and impaired self-realization than other student $^{10}$. A study was done in Italy in 2011 about "Knowledge and attitudes toward epilepsy among primary and secondary schoolteachers in Italy". It was conducted on a random sample of 600 of Italian schoolteachers through a nationwide telephone interview, the result shows different knowledge and attitude among the teachers, around half of them believed epilepsy hereditary and incurable, and more than one third of them thought it requires support at school $^{11}$.

In 2011 done a study in Gezira State, Sudan about Knowledge, practice and attitude toward epilepsy among Two hundred primary and secondary school teachers, they found that the majority of them had never informed about epilepsy nor previously trained to deal with it. Some of teachers considered epilepsy as an attack from a demon or contagious. About $64 \%$ of secondary schoolteachers had knowledge of the initial behaviour toward a child with seizure compared to primary schoolteacher, which shows only $47 \%^{12}$. A study was conducted by self-administered questionnaire on 189 teachers in Egypt 2010 about "Knowledge, attitude and practice with respect to epilepsy among school teachers in Assiut city, Egypt". Result show that all teachers had heard about epilepsy, and more than half of them deal with epileptic students as normal students ${ }^{13}$.

A study was in 2008about "Knowledge awareness and attitude about epilepsy among schoolteachers of primary and secondary levels in India". Theresults show that the majority of schoolteachers were aware that epilepsy is a brain disease. More than $30 \%$ were unsure if epilepsy is related to insanity, and have low IQ. Half of them allow their children to play with an epileptic. $27 \%$ only had given first aid to epileptic fit, and only $16 \%$ giving it properly ${ }^{14}$. A study published in 2005 about "Perception and attitude to epilepsy among teachers in primary, secondary and tertiary educational institutions in middle belt Nigeria". It was conducted on 460 schoolteachers, and found that even though almost the entire almost teacher had heard about epilepsy negative attitude towards epilepsy is still there. More than half did not knew the cause of epilepsy and several of them had wrong information on the etiology. Some of them misunderstood epilepsy for insanity ${ }^{15}$. In 2004 done "A study on awareness and attitude of teachers on epilepsy in Istanbul" the study done among 346 teachers, and it was showed that more than half of teachers heard about epilepsy, while $71.9 \%$ attended seizure attack, and 59.4\% knew someone with epilepsy. There was some misconceptions like $2.3 \%$ think epilepsy is contagious, or a psychological disease $17.8 \%{ }^{16}$.

In 2002 a study about "Awareness, attitudes and understanding towards epilepsy among schoolteachers in Medan, Indonesia", they found that $16 \%$ of the teachers are well informed about epilepsy, and there are significant proportion had negative attitude and misunderstanding the disease ${ }^{17}$.A study was conducted in 2001. About "knowledge and attitudes toward epilepsy among primary, secondary and tertiary levelteachers ". Among 300 teacher, show that almost all the teachers had heard about epilepsy, some teacher believe that the epilepsy either contagious or they don't know, and (43\%) of teachers had knowledge of the initial procedures during a seizure ${ }^{18}$. The goal of this study was to assess the awareness about the definition of Epilepsy in pediatric ages, types of epilepsy, managing an epileptic fit in children and awareness about the impact of epilepsy on children's educational and social performance among schoolteachers.

\section{Materials and Methods:-}

A cross-sectional study with a 14 Statement questionnaire about epilepsy knowledge was administered to teachers at general and private educational schools in Riyadh, KSA. The study was conducted for 6 weeks and starting November 2016. 32 schools were chosen randomly to be part of the study.

The questionnaire was designed to assess the knowledge among teachers about definition, types, management of epilepsy and epileptic fit and its impact on children's social and educational performance in school aged children. Teachers gave written consent before conducting the study.

The variables under study were having heard about epilepsy, sources of information about the disease, types of the disease, possible causes, theneed of more knowledge about the disease, the differences when comparing epileptic children's behavior and school performance to their classmates, and finally whether they have ever encountered an epileptic fit, their first reaction and steps taken during management. 


\section{Ethical approval:-}

The study was approved by the ethical committee at College of Medicine of Al Maarefa Colleges followed by approval of the ministry of education, Riyadh, Kingdom of Saudi Arabia.

\section{Statistical analysis:-}

After completion of data collection, it was reviewed, organized, tabulated and then statistically analyzed using percentages and frequencies

\section{Results:-}

The study conducted in Riyadh city KSA. The data was obtained from 320 teachers from different schools .The response rate was $100 \%$, but many questions were unanswered. It was found $5.4 \%$ of teachers teaching kindergarten students, $37.2 \%$ teaching primary students, $35.3 \%$ teaching intermediate students and $22.1 \%$ teaching secondary students. $99.4 \%$ of teachers have heard about epilepsy, while $0.6 \%$ hasn't heard about epilepsy. Most of the teachers want to learn more about epilepsy, which represent $96.6 \%$, while $3.4 \%$ don't care about it. About $73 \%$ of teachers know that one type of seizure is generalized seizure, $35.9 \%$ know partial seizure, $11 \%$ know complex partial seizure, $30 \%$ know absence seizure, 23\% know generalized tonic clinic seizure, 28\% know status epileptics and 7.7\% know pseudo seizure (Table 1).

Table 1:-Demographic characteristics and epilepsy Knowledge among teachers.

\begin{tabular}{|l|l|l|}
\hline & Frequency & Percent \\
\hline Levels of teachers: & & \\
\hline Kindergarten & 17 & $5.4 \%$ \\
\hline Primary & 118 & $37.2 \%$ \\
\hline Intermediate & 112 & $35.3 \%$ \\
\hline Secondary & 70 & $22.1 \%$ \\
\hline Total & 320 & $100 \%$ \\
\hline Heard about epilepsy: & & \\
\hline Yes & 315 & $99.4 \%$ \\
\hline No & 2 & $0.6 \%$ \\
\hline Total & 320 & $100 \%$ \\
\hline Need to now about epilepsy: & & \\
\hline Yes & 308 & $96.6 \%$ \\
\hline No & 11 & $3.4 \%$ \\
\hline Total & 320 & $100 \%$ \\
\hline Types of seizure: & & \\
\hline Generalized seizure & 199 & $72.9 \%$ \\
\hline Partial seizure & 98 & $35.9 \%$ \\
\hline Complex partial seizure & 30 & $11 \%$ \\
\hline Absence seizure & 84 & $30.8 \%$ \\
\hline Generalized tonic clonic seizure & 63 & $23.1 \%$ \\
\hline Status epileptics & 78 & $28.6 \%$ \\
\hline Pseudo seizure & 21 & $7.7 \%$ \\
\hline
\end{tabular}

It was found $55.2 \%$ of teachers have been a witness of an epileptic fit in their classes and $44.8 \%$ haven't been. $43 \%$ of teachers' first reaction to an epileptic fit was trying to help, $10.5 \%$ was feeling afraid and steeping back, $19.8 \%$ was calling for help and standing by and about $27 \%$ don't know what to do. $59 \%$ of teachers know the first aid in epileptic fit, $41.4 \%$ don't know (Table 2). 
Table 2:- Comparison between teachers in dealing with a case requiring epilepsy.

\begin{tabular}{|l|l|l|}
\hline & Frequency & Percent \\
\hline Witness of an epileptic fit in class: & & \\
\hline Yes & 99 & $44.8 \%$ \\
\hline No & 122 & $55.2 \%$ \\
\hline Total & 320 & $100 \%$ \\
\hline First reaction: & & \\
\hline Feel afraid and step back & 18 & $10.5 \%$ \\
\hline Go and help & 74 & $43 \%$ \\
\hline Call for help and stand by & 34 & $19.8 \%$ \\
\hline I don't know what to do & 46 & $26.7 \%$ \\
\hline Total & 320 & $100 \%$ \\
\hline Knowing first aid: & & \\
\hline Yes & 136 & $58.6 \%$ \\
\hline No & 96 & $41.4 \%$ \\
\hline Total & 320 & $100 \%$ \\
\hline
\end{tabular}

It was found $70 \%$ of teachers think that one of the first aid in epileptic fit is to Put a soft towel in the mouth to protect the tongue and keep airway open, $46.3 \%$ think to Secure the media around the patient, remove all harmful objects and put him on his left side, $43.6 \%$ think to try to put hard object in the mouth to protect the tongue and keep mouth open, $21.6 \%$ think to try to use any perfume to wake him up, $11.5 \%$ think to give him some water and about $10 \%$ think to give him his medication during the attack (Table 3).

Table 3:-Comparison between teachers in dealing with a case requiring first aid.

\begin{tabular}{|l|l|l|}
\hline First aid: & Frequency & Percent \\
\hline $\begin{array}{l}\text { Try to put hard object in the mouth } \\
\text { to protect the tongue and keep } \\
\text { mouth open }\end{array}$ & 99 & $43.6 \%$ \\
\hline $\begin{array}{l}\text { Secure the media around the patient, } \\
\text { remove all harmful objects and put } \\
\text { him on his left side. }\end{array}$ & 105 & $46.3 \%$ \\
\hline $\begin{array}{l}\text { Put a soft towel in the mouth to } \\
\text { protect the tongue and keep airway } \\
\text { open. }\end{array}$ & 160 & $70.5 \%$ \\
\hline $\begin{array}{l}\text { Try to use any perfume to wake him } \\
\text { up. }\end{array}$ & 49 & $21.6 \%$ \\
\hline Give him some water & 26 & $11.5 \%$ \\
\hline $\begin{array}{l}\text { Give him his medication during the } \\
\text { attack. }\end{array}$ & 23 & $10.1 \%$ \\
\hline
\end{tabular}

It was found about $38 \%$ of teachers know epilepsy from media, $22.1 \%$ from friends, $19.4 \%$ from relatives, $12 \%$ from affected member in their families and $8.4 \%$ from other sources (Figure 1). 


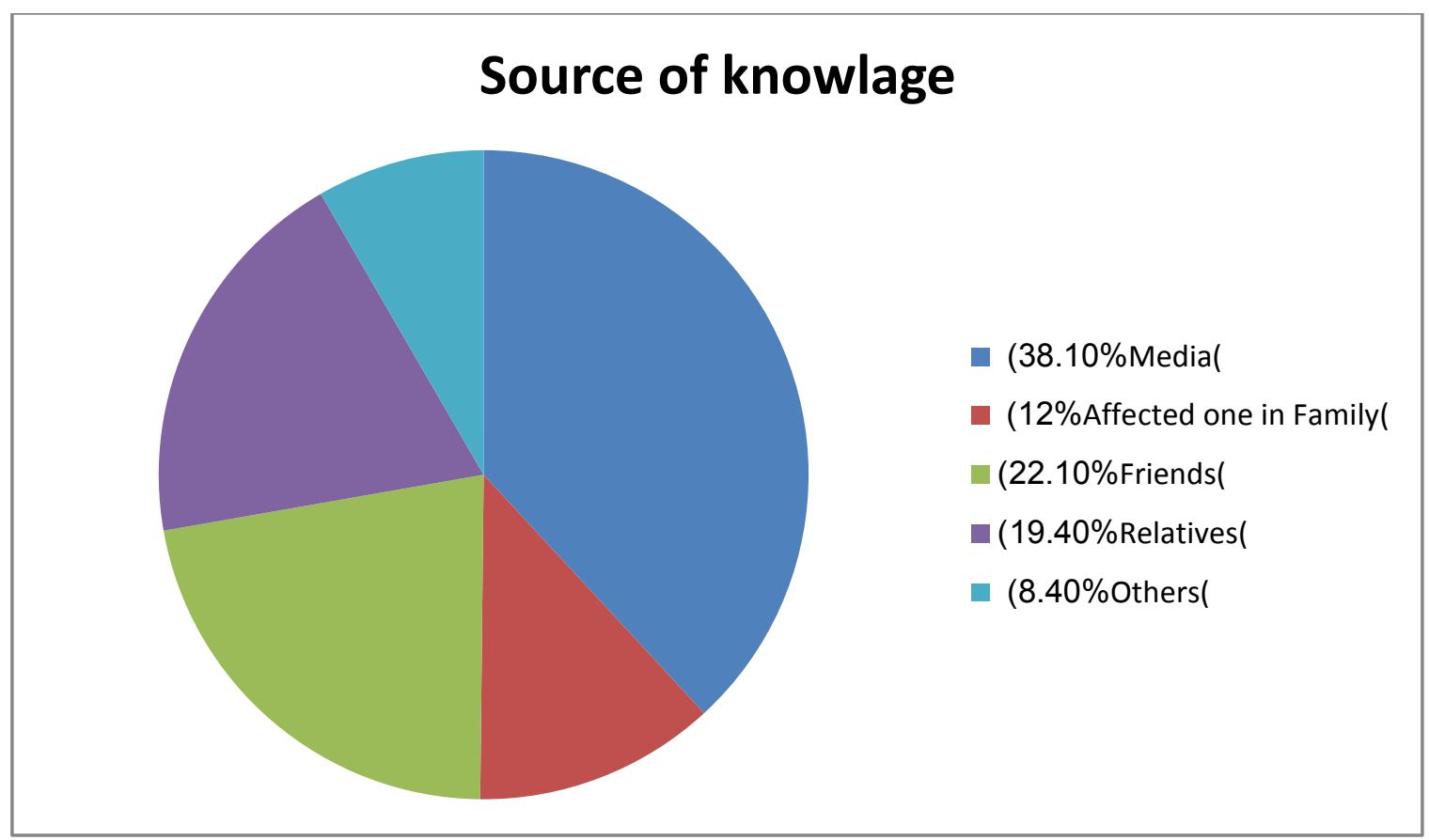

Figure 1:-source of knowledge about epilepsy among teachers.

It was found $70.3 \%$ of teachers think one cause of epilepsy is an abnormal electrical activity in the brain, $23.8 \%$ think it's from brain trauma, $21.6 \%$ from brain infections, $14.4 \%$ from genetic defect, 14.1 from anxiety and stress, $7.8 \%$ from birth defect, $4.1 \%$ from brain cancer and about $12 \%$ don't know the cause (Figure 2).

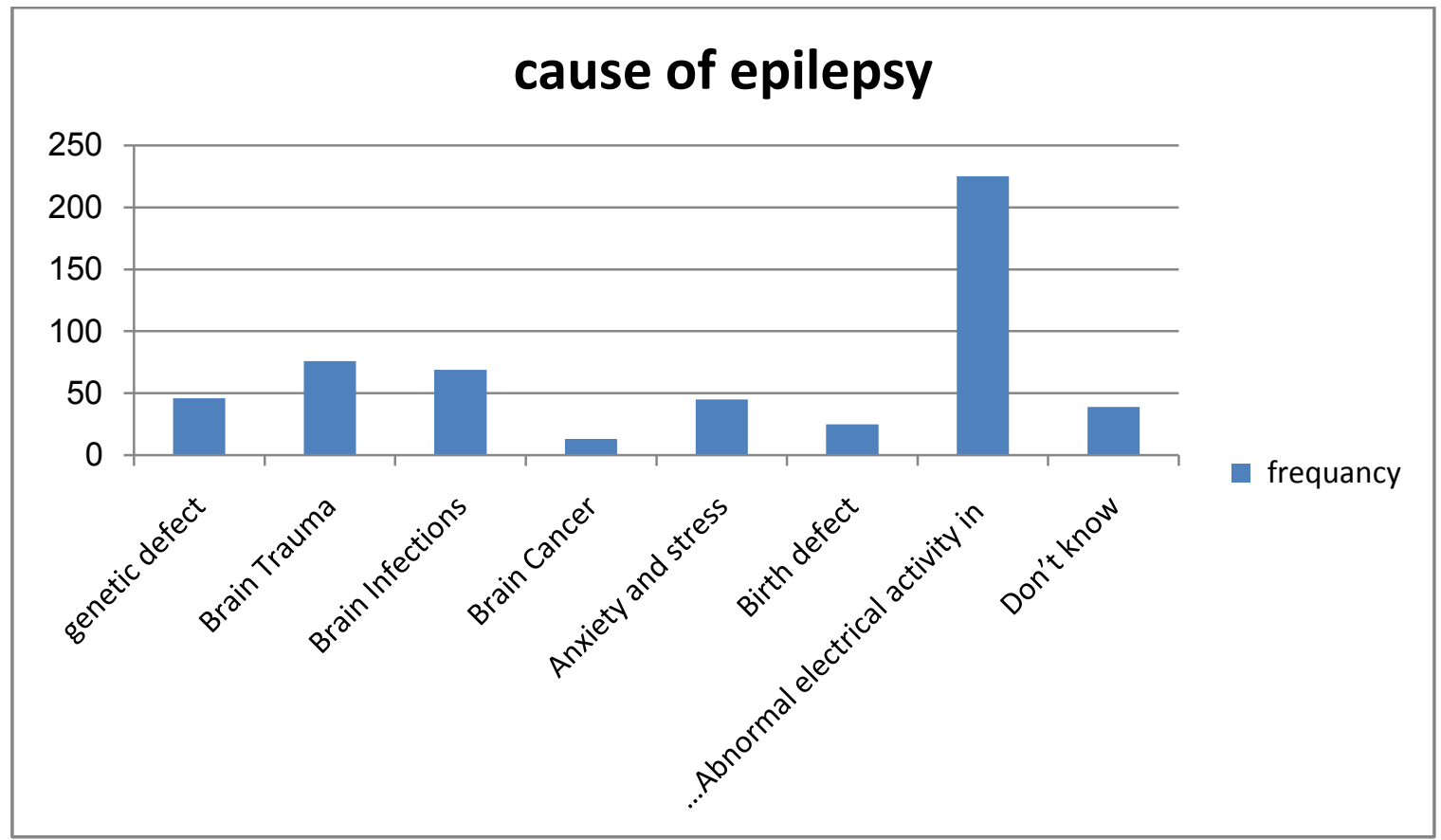

Figure 2:-Opinion about cause of epilepsy among teachers.

It was found most of teachers think that epilepsy is a neurological disease witch represent about $84 \%, 6.9 \%$ think it's psychiatric disease, $5 \%$ think it's hereditary disease and $4.4 \%$ think it's from evil spirit or spell. It was found $83.3 \%$ of teacher thinks that there are many types of seizure and about $16.7 \%$ don't think. It was found $55.7 \%$ of teachers notice that an epileptic student doesn't have low school performance, $39 \%$ notice some of them and 5.2\% notice 
they have low school performance. It was found $4.5 \%$ of teachers notice an epileptic student have social behavior issues, $34.2 \%$ notice some of them and $61 \%$ don't notice.

\section{Discussion:-}

Awareness about epilepsy is considered very important to the society in general, and among school teachers becomes even more, as they are in contact with children for long hours on daily basis, which makes them more prone to encounter epileptic fits or other emergencies. Therefore this research was made to assess the awareness of schoolteachers about epilepsy and how to manage an epileptic fit among children.

In our study, a sample made of 300 male/female teachers, from deferent levels, ranging from kindergarten to secondary grades. The majority were primary school teachers. Almost all of the teachers heard about epilepsy, from deferent sources, mostly from media. However, the majority emphasizes the fact that they want to know more about epilepsy.

There are deferent believes among people in the society regarding the nature of the disease, this intern, can affect how people adapt and behave towards it, many people are shy to even tell that they have an epileptic member in the family. In our study we found that most of teachers think that epilepsy is a neurological disease, in contrast to a study that was done in Italy in 2011 about "Knowledge and attitudes toward epilepsy among primary and secondary schoolteachers in Italy" that showed half of the sample believed epilepsy is a hereditary and incurable disorder. Surprisingly still there are some who think that epilepsy is a result of power from evil spirit. In another study done in Gezira State, Sudan about Knowledge, practice and attitude toward epilepsy among Two hundred primary and secondary school teachers, Some of teachers considered epilepsy as an attack from a demon or contagious.

The majority of the sample has a good knowledge about the cause of the disorder as they mention the correct answer that it is abnormal electrical activity in the brain.

In this study the majority of the school teachers knew that seizure has different types but mostly recognized generalized tonic clonic seizure and only one third of the sample knew about partial seizure, although a study that was made in Finland about" Distribution of seizure types in an epileptic population". ", and showed that partial seizure accounts for $50 \%$ of epileptic disorders in children.

When teachers were asked about low school performance, more than half of the study sample noticed that epileptic students don't have a low school performance. And this result is supported by a study made in Nigeria about Academic performance of school children with epilepsy and ${ }^{2}$ where they found that the overall academic performance of epileptic children without other chronic disorders attending normal schools is not different from that of normal children in the same setting, though they are under-achieving in some subjects.

In regards of the impact of the disorder on social behavior of epileptic children most of the teachers didn't notice any behavioral issues.

This studyshowed that there is no significant differences in the number of teachers have been a witness of an epileptic fit in their classes and thosewho haven't been. However, less than the half percentage of our sample had attended epileptic fits. In comparison with other researches that have same sample conducted in different cities in Saudi Arabia, it indicate d that the teachers in Khamis Mushate and Southern Saudi Arabia have attended epileptic fits more than in Riyadh, and Jeddah had the least attendance.In our study results, we found that most of schoolteachers know how to provide first aid when seizure attacks happened in classrooms, this was noticed by choosing the correct steps of management that was asked in the questionnaire. However, still there is more than half percentage of schoolteacher's think that they need more knowledge in handling a situation of an epileptic fit. As our study showed that most of our sample knew about epilepsy, however, the majority as well didn't know how to deal with an epileptic fit. This finding was similar to many other studies conducted about "knowledge and practice of school teachers toward students with epilepsy in Khamis Mushate, Southern Saudi Arabia, West of Iran, Jeddah, Jordan, Egypt, India, Indonesia and Italy". Gezira state and Sudan, showed higher percentage of knowledge about the initial steps taken toward a seizing child. When asking about the first aid in managing a child who is seizing, many teachers choose to put a soft towel in the mouth to protect the tongue and keep airway open and only Few teachers choose to secure the media around the patient and remove all harmful objects and put him on his left side and try to put hard object in the mouth to protect the tongue and keep mouth open.This study has confirmed that 
most of schoolteachers have poor knowledge of how to deal with seizure attack as first aid. And accordingly we need to arrange more school activities talking about the awareness of epilepsy and let the teachers do practical application of first-aid management of epileptic patient.

\section{Conclusion:-}

This study has revealed a critical issue that a majority of schoolteachers do not have adequate knowledge about epilepsy. We recommend the mandatory implementation of epilepsy and basic life-support training and refreshing courses for all schoolteachers across KSA. In addition to enrolling in training courses, teachers must be aware of the availability of first aid kits at schools and the contact numbers of the Saudi Red Crescent Services.

\section{Authors' contribution:-}

All authors took part equally in writing, revising and final approval of the manuscript.

\section{Conflict of interest:-}

The authors have no conflict of interest to declare.

\section{Acknowledgements:-}

We would like to thank professor dr. Fawzia Ahmed Habib and associate professor dr. Basel Abdulbaset Alkahilfor there helpful supervision and contributions to this the study. We are also grateful to the ministry of education leadership and all teachers participating in this study.

\section{References:-}

1. Sonia A. Khan, MD, FRCP. Epilepsy awareness in Saudi Arabia.Neurosciences (Riyadh). 2015 Jul; 20(3): 205206.

2. David Y Ko, MD. "Epilepsy and Seizures",medscape.com,22/10/2016.

3. "Epilepsy Impact on the Life of the Child", epilepsy foundation, epilepsy.com, 2014.

4. Eman Al-Hashemi, AbdullatifAshkanani, Haneen Al-Qattan, Asmaa Mahmoud, Majd Al-Kabbani, Abdulaziz Al-Juhaidli, Ahmad Jaafar, and Zahraa Al-Hashemi. Knowledge about Epilepsy and Attitudes toward Students with Epilepsy among Middle and High School Teachers in Kuwait. International Journal of Pediatrics, Volume 2016 (2016), Article ID 5138952, 15 pages.

5. Jobran M. Alqahtani. Knowledge and practice of schoolteachers towards students with epilepsy in Khamis Mushate, Southern Saudi Arabia.J Family Community Med. 2015 Sep-Dec; 22(3): 163-168

6. NargesKarimi and Mohammad Heidari. Knowledge and attitudes toward epilepsy among school teachers in West of Iran.Iran J Neurol. 2015 Jul 6; 14(3): 130-135.

7. NashaHomiBhesania, Anaya Rehman, IlmaSalehSavul, and NosheenZehra. Knowledge, attitude and practices of school teachers towards epileptic school children in Karachi, Pakistan.Pak J Med Sci. 2014 Jan-Feb; $30(1)$ : $220-224$.

8. Albaraa S. Abulhamail, Fahad E. Al-Sulami, Mouneeb A. Alnouri, Najeeb M. Mahrous, Dima G. Joharji, Maha M. Albogami, Mohammed M. Jan. Primary school teacher's knowledge and attitudes toward children with epilepsy. Seizure European Journal of Epilepsy, April 2014 Volume 23, Issue 4, Pages 280-283

9. HatemAlkhamra,AdelTannous, MunaHadidi, Jamal Alkhateeb.Knowledge and attitudes toward epilepsy among school teachers and counselors in Jordan. Epilepsy \& Behavior J, August 2012Volume 24, Issue 4, Pages 430434.

10. Dana Brabcovaa, VladimiraLovasovab, Jiri Kohoutc and Jana Zarubovad. Familiarity with and attitudes towards epilepsy among teachers at Czech elementary schools-The effect of personal experience and subspecialization. Seizure European Journal of Epilepsy, July 2012, Volume 21, Issue 6, Pages 461-465.

11. OrianoMecarelli, Giuseppe Capovilla, Antonino Romeo, Guido Rubboli, Paolo Tinuper, EttoreBeghi. Knowledge and attitudes toward epilepsy among primary and secondary schoolteachers in Italy. Epilepsy \& Behavior J, October 2011Volume 22, Issue 2, Pages 285-292.

12. Haydar E Babikar, andIslam M Abbas. Knowledge, practice and attitude toward epilepsy among primary and secondary school teachers in South Gezira locality, Gezira State, Sudan. J Family Community Med. 2011 JanApr; 18(1): 17-21.

13. Ghaydaa A. Shehata, Dalia G. Mahran. Knowledge, attitude and practice with respect to epilepsy among school teachers in Assiut city, Egypt. Epilepsy Research ,December 2010 Volume 92, Issues 2-3, Pages 191-200. 
14. Anup K. Thacker, Anand M. Verma , Ram Ji, Prolima Thacker, Pragya Mishra.Knowledge awareness and attitude about epilepsy among schoolteachers of primary and secondary levels in India. Seizure European Journal of Epilepsy ,December 2008 volume 17, Issue 8,Pages 684-690.

15. E O Sanya, T A T Salami, O O Goodman, O I N Buhari and M O Araoye. Perception and attitude to epilepsy among teachers in primary, secondary and tertiary educational institutions in middle belt Nigeria. Tropical Doctor, July 1, 2005, Vol 35, Issue 3, pages 153-156.

16. NuralBekiroğlu, RefikaÖzkan, CandanGürses. A study on awareness and attitude of teachers on epilepsy in Istanbul. Seizure European Journal of Epilepsy, October 2004 Volume 13, Issue 7, Pages 517-522.

17. Aldy S RAMBE, Hasan SJAHRIR. Awareness, attitudes and understanding towards epilepsy among school teachers in Medan, Indonesia. Neurol J Southeast Asia 2002; $7: 77$ - 80.

18. FábioGalvãoDantas, Gibran Agra Cariri, Gustavo Agra Cariri, Antônio Roberto VazRibeiroFilho. KNOWLEDGE AND ATTITUDES TOWARD EPILEPSY AMONG PRIMARY, SECONDARY AND TERTIARY LEVEL TEACHERS. Arq. Neuro-Psiquiatr. vol.59 no.3B São Paulo Sept. 2001.

19. Keränen T1, Sillanpää M, Riekkinen PJ. Distribution of seizure types in an epileptic population. Epilepsia. 1988 Jan-Feb;29(1):1-7.

20. Ibekwe RC1, Ojinnaka NC, Iloeje SO.Academic performance of school children with epilepsy. West Afr J Med. 2008 Apr;27(2):74-7. 